\title{
Purinergic Signaling in the Central Nervous System in Health and Disease
}

\author{
Peter Illes ${ }^{1,2} \cdot$ Guang-Yin $\mathrm{Xu}^{3}$ (1) Yong Tang ${ }^{1,4}$
}

Received: 23 September 2020/ Accepted: 14 October 2020/Published online: 4 November 2020

(C) Shanghai Institutes for Biological Sciences, CAS 2020

The existence of purinergic signaling — the idea that almost all cells of the animal/human organism are able to communicate with each other via extracellular purineswas proposed by Geoffrey Burnstock (1929-2020) in 1972 [1-3]. The purinergic system includes the following constituents: (1) the four main purines: adenosine triphosphate (ATP) and its metabolites, adenosine diphosphate (ADP), adenosine monophosphate (AMP), and adenosine (ADO); (2) three key enzymes, the ectonucleoside triphosphate diphosphohydrolases (E-NTPDases: NTPDase 1/CD39), ectonucleotide pyrophosphatase/phosphodiesterases (E-NPP), and ecto-5'-nucleotidase (E-5'-nucleotidase/CD73), which decompose ATP into ADP, AMP, and ADO; and (3) nineteen purinergic receptors: four subtypes of $\mathrm{G}$ protein-coupled $\mathrm{P} 1$ receptors (A1, A2A, A2B, and $\mathrm{A} 3)$, seven subtypes of ligand-gated cationic channels (P2X1-7), and eight subtypes of metabotropic G proteincoupled receptors (P2Y1, 2, 4, 6, and 11-14) [4, 5]. ATP was described originally as a co-transmitter with classic transmitters such as noradrenaline and acetylcholine in the peripheral vegetative nervous system [6]. Later, ATP was identified as a transmitter and signaling molecule in its own

Yong Tang

tangyong@cdutcm.edu.cn

1 International Collaborative Centre on Big Science Plan for Purine Signaling, Chengdu University of Traditional Chinese Medicine, Chengdu 610075, China

2 Rudolf-Boehm-Institut für Pharmakologie und Toxikologie, Universitaet Leipzig, Leipzig 04107, Germany

3 Institute of Neuroscience, Soochow University, Suzhou 215123, China

4 Acupuncture and Chronobiology Key Laboratory of Sichuan Province, Chengdu 610075, China right and a molecule participating in intercellular signal transduction [7]. In the central nervous system (CNS), purinergic signaling plays an important role in maintaining the functions of neurons, astrocytes, and microglia, and regulating their homeostasis, with consequences for synaptic transmission and higher-order cognitive processes [8, 9]. For instance, ADO and the activation of A1 receptors contribute to sleep homeostasis $[10,11]$, while in contrast, the inhibition of $\mathrm{A} 2 \mathrm{~A}$ receptors leads to sleep disorder [12]. Furthermore, neuronal P2X3 receptors (mainly expressed in neurons) and glial $\mathrm{P} 2$ receptors (P2X4, P2X7, P2Y1, and P2Y12 in microglia; P2X7 and $\mathrm{P} 2 \mathrm{Y} 1$ receptors in astrocytes; $\mathrm{P} 2 \mathrm{X} 7, \mathrm{P} 2 \mathrm{Y} 1$, and $\mathrm{P} 2 \mathrm{Y} 12$ receptors in oligodendrocytes) have been demonstrated to participate in neuroinflammation or neuron-microglia, neuron-astrocyte, and neuron-oligodendrocyte interactions, as well as microglia-neuron, astrocyte-neuron, and oligodendrocyte-neuron interactions, and finally in astrocytemicroglia and microglia-oligodendrocyte interactions [13-17]. In recent decades, the pathological potential of purinergic signaling that contributes to and aggravates various types of neurodegenerative illnesses (Alzheimer's, Parkinson's and Huntington's disease as well as multiple sclerosis and amyotrophic lateral sclerosis) has been increasingly acknowledged $[8,9,18,19]$. Nucleotides are also fundamental for the pathological evolution of trauma, ischemia, stroke, and epilepsy, in which they mediate both acute and secondary neurodegeneration $[20,21]$. In the clinic, single nucleotide polymorphisms of A2A and P2X7 receptors may serve as potential indicators for the early risk assessment of CNS disorders [22-24]. Drugs (such as istradefylline, dipyridamole, suramin, clopidogrel, prasugrel, cangrelor, and ticagrelor) targeted to purinergic signaling and approved by the US Food and Drug Administration have beneficial effects on a variety of 
neurological diseases [25-27] and further drugs still in development may open new avenues in fighting a multitude of CNS diseases [28, 29].

Three original articles, 4 reviews, and 1 insight paper are included in this special topic. Li et al. [30] demonstrated that an increased concentration of extracellular ATP and activated astroglial P2X7 receptors are responsible for chronic sleep deprivation-induced depressive-like behavior in mice. Engel et al. [31] used a transgenic mouse model overexpressing P2X7 fused to the fluorescent protein EGFP to visualize $\mathrm{P} 2 \mathrm{X} 7$ receptor expression. They found that increased P2X7-EGFP expression was localized in microglia and oligodendrocytes of the hippocampus, cortex, striatum, thalamus, and cerebellum after intra-amygdala kainic acid injection that caused epilepsy or even status epilepticus. Xu et al. [32] showed that neonatal maternal deprivation followed by adult multiple stress led to P2X3 receptor activation, which is most likely mediated by upregulation of $\beta 2$ adrenergic signaling in primary sensory neurons, thus contributing to visceral hypersensitivity. Milenkovic et al. [33] concentrated on purinergic modulation of neuronal activity in the developing auditory system and provided new models of the contribution of purinergic signaling to early development of the afferent auditory pathway. The review by Boue-Grabot et al. [34] focused on the contribution of neuronal and glial P2X4 receptors to pathological CNS states and proposed that these receptors are a potential therapeutic target in CNS diseases. Ulrich et al. [35] discussed the role of purinergic receptors in the molecular mechanisms shared by Huntington's and Parkinson's diseases and proposed that A2A and $\mathrm{P} 2 \mathrm{X} 7$ receptor antagonists might be promising therapeutic agents for their treatment. Frenguelli et al. [36] summarized the developments in translational research on purines from diagnostic biomarkers to therapeutic agents in brain injury. In the insight of Illes et al. [37], it is pointed out that the decreased astrocytic release of ATP and activation of $\mathrm{P} 2 \mathrm{X} 7$ receptors in the medial prefrontal cortex and hippocampus may play important roles in the development of major depressive disease.

We strongly believe that the comprehensive reviews listed above allow profound insights into the purinergic modulation of CNS functions in health and disease, and thereby represent a significant increase of our knowledge in the purine field.

Acknowledgements This Editorial is dedicated to the memory of recently deceased Professor Geoffrey Burnstock. It was supported by grants from the National Key R\&D Program of China (2019YFC1709101), the Project First-Class Disciplines Development of Chengdu University of Traditional Chinese Medicine (CZYHW1901), and the Science and Technology Program of Sichuan Province, China (2019YFH0108).

\section{References}

1. Burnstock G. Purinergic nerves. Pharmacol Rev 1972, 24: 509-581.

2. Abbracchio MP, Jacobson KA, Müller CE, Zimmermann H. Professor Dr. Geoffrey Burnstock (1929-2020). Purinergic Signalling 2020, 16: 137-149.

3. Verkhratsky A, Zimmermann H, Abbracchio MP, Illes P, Di Virgilio F. In Memoriam Geoffrey Burnstock: Creator of Purinergic Signaling. Function 2020, 1: zqaa006. https://doi. org/10.1093/function/zqaa006.

4. Ralevic V, Burnstock G. Receptors for purines and pyrimidines. Pharmacol Rev 1998, 50: 413-492.

5. Jacobson KA, Müller CE. Medicinal chemistry of adenosine, P2Y and P2X receptors. Neuropharmacology 2016,104: 31-49.

6. Burnstock G. The fifth Heymans memorial lecture-Ghent, February 17, 1990. Co-transmission. Arch Int Pharmacodyn Ther 1990, 304: 7-33.

7. Burnstock G. The past, present and future of purine nucleotides as signalling molecules. Neuropharmacology 1997, 36: 1127-1139.

8. Burnstock G. Purinergic signalling and neurological diseases: An update. CNS Neurol Disord Drug Targets 2017, 16: 257-265.

9. Burnstock G. Introduction to purinergic signalling in the brain. Adv Exp Med Biol 2020,1202: 1-12.

10. Gvilia I, Suntsova N, Kostin A, Kalinchuk A, McGinty D, Basheer $\mathrm{R}$, et al. The role of adenosine in the maturation of sleep homeostasis in rats. J Neurophysiol 2017, 117: 327-335.

11. Peng W, Wu Z, Song K, Zhang S, Li Y, Xu M. Regulation of sleep homeostasis mediator adenosine by basal forebrain glutamatergic neurons. Science 2020, 369: eabb0556.

12. Lazarus M, Oishi Y, Bjorness TE, Greene RW. Gating and the need for sleep: Dissociable effects of adenosine A1 and A2A receptors. Front Neurosci 2019, 13: 740.

13. Illes P, Burnstock G, Tang Y. Astroglia-derived ATP modulates CNS neuronal circuits. Trends Neurosci 2019, 42: 885-898.

14. Cserép C, Pósfai B, Lénárt N, Fekete R, László ZI, Lele Z, et al. Microglia monitor and protect neuronal function through specialized somatic purinergic junctions. Science 2020, 367: 528-537.

15. Illes $\mathrm{P}$, Rubini $\mathrm{P}$, Ulrich $\mathrm{H}$, Zhao $\mathrm{Y}$, Tang $\mathrm{Y}$. Regulation of microglial functions by purinergic mechanisms in the healthy and diseased CNS. Cells 2020, 9: 1108.

16. Rivera A, Vanzulli I, Butt AM. A central role for ATP signalling in glial interactions in the CNS. Curr Drug Targets 2016, 17: $1829-1833$.

17. Illes $\mathrm{P}$, Verkhratsky A. Purinergic neurone-glia signalling in cognitive-related pathologies. Neuropharmacology 2016, 104: $62-75$.

18. Illes P, Verkhratsky A, Burnstock G, Sperlagh B. Purines in neurodegeneration and neuroregeneration. Neuropharmacology 2016, 104: 1-3.

19. Illes P, Verkhratsky A, Tang Y. Pathological ATPergic signaling in major depression and bipolar disorder. Front Mol Neurosci 2020, 12: 331.

20. Inoue K, Koizumi S, Tsuda M. The role of nucleotides in the neuron-glia communication responsible for the brain functions. $\mathrm{J}$ Neurochem 2007, 102: 1447-1458.

21. Miras-Portugal MT, Gomez-Villafuertes R, Gualix J, DiazHernandez JI, Artalejo AR, Ortega F, et al. Nucleotides in neuroregeneration and neuroprotection. Neuropharmacology 2016, 104: 243-254.

22. Oliveira S, Ardais AP, Bastos CR, Gazal M, Jansen K, de Mattos Souza L, et al. Impact of genetic variations in ADORA2A gene on depression and symptoms: a cross-sectional population-based study. Purinergic Signal 2019, 15: 37-44. 
23. Vereczkei A, Abdul-Rahman O, Halmai Z, Nagy G, Szekely A, Somogyi A, et al. Association of purinergic receptor P2RX7 gene polymorphisms with depression symptoms. Prog Neuropsychopharmacol Biol Psychiatry 2019, 92: 207-216.

24. Sanz JM, Falzoni S, Rizzo R, Cipollone F, Zuliani G, Di Virgilio F. Possible protective role of the 489C $>\mathrm{T}$ P2X7R polymorphism in Alzheimer's disease. Exp Gerontol 2014, 60: 117-119.

25. Chen JF, Cunha RA. The belated US FDA approval of the adenosine A2A receptor antagonist istradefylline for treatment of Parkinson's disease. Purinergic Signal 2020, 16: 167-174.

26. Burnstock G. The therapeutic potential of purinergic signalling. Biochem Pharmacol 2018, 151: 157-165.

27. Burnstock, G. Purinergic signalling and disorders of the central nervous system. Nat Rev Drug Discov 2008, 7: 575-590.

28. Schilling U, Dingemanse J, Ufer M. Pharmacokinetics and pharmacodynamics of approved and investigational P2Y12 receptor antagonists. Clin Pharmacokinet 2020, 59: 545-566.

29. Burnstock G. Introduction to purinergic signaling. Methods Mol Biol 2020, 2041: 1-15.

30. Xia M, Li Z, Li S, Liang S, Li X, Chen B, et al. Sleep deprivation selectively down-regulates astrocytic $5-\mathrm{HT}_{2 \mathrm{~B}}$ receptors and triggers depressive-like behaviors via stimulating P2X7 receptors in mice. Neurosci Bull 2020, 36: 1259-1270. https://doi.org/10. 1007/s12264-020-00524-4.

31. Morgan J, Alves M, Conte G, Menéndez-Méndez A, de DiegoGarcia L, de Leo G, et al. Characterization of the expression of the ATP-Gated P2X7 receptor following status epilepticus and during epilepsy using a P2X7-EGFP reporter mouse. Neurosci Bull 2020, 36: 1242-1258. https://doi.org/10.1007/s12264-02000573-9.

32. Hu S, Sun Q, Du WJ, Song J, Li X, Zhang PA, et al. Adult stress promotes purinergic signaling to induce visceral pain in rats with neonatal maternal deprivation. Neurosci Bull 2020, 36: 1271-1280. https://doi.org/10.1007/s12264-020-00575-7.

33. Jovanovic S, Milenkovic I. Purinergic modulation of activity in the developing auditory pathway. Neurosci Bull 2020, 36: 1285-1298. https://doi.org/10.1007/s12264-020-00586-4.

34. Duveau A, Bertin E, Boué-Grabot E. Implication of neuronal versus microglial $\mathrm{P} 2 \mathrm{X} 4$ receptors in central nervous system disorders. Neurosci Bull 2020, 36: 1327-1343. https://doi.org/10. 1007/s12264-020-00570-y.

35. Glaser T, Andrejew R, Oliveira-Giacomelli Á, Ribeiro DE, Bonfim Marques L, Ye Q, et al. Purinergic receptors in basal ganglia diseases: shared molecular mechanisms between huntington's and parkinson's disease. Neurosci Bull 2020, 36: 1299-1314. https://doi.org/10.1007/s12264-020-00582-8.

36. Frenguelli BG, Dale N. Purines: From diagnostic biomarkers to therapeutic agents in brain injury. Neurosci Bull 2020, 36: 1315-1326. https://doi.org/10.1007/s12264-020-00529-z.

37. Illes $\mathrm{P}$, Rubini $\mathrm{P}$, Yin $\mathrm{H}$, Tang Y. Impaired ATP release from brain astrocytes may be a cause of major depression. Neurosci Bull 2020, 36: 1281-1284. https://doi.org/10.1007/s12264-02000494-7. 